\title{
JOÃO DE BARROS E EVANILDO BECHARA, GRAMÁTICAS DOS SÉCULOS XVI E XXI: O PRETÉRITO MAIS-QUE-PERFEITO E 0 ENSINO DE LÍNGUA PORTUGUESA
}

\section{VICTOR HUGO RAIMÃO FERNANDES}

Mestrando em Língua Portuguesa pela Pontifícia Universidade Católica de São Paulo (PUC-SP).

E-mail: victor.fernandes@live.com

\section{Resumo}

Este trabalho visa formar uma reflexão sobre o ensino do tempo-modo verbal pretérito mais-que-perfeito do indicativo em escolas públicas de Educação Básica (Ensino Médio) a partir de uma análise da descrição desses tempos verbais em duas gramáticas, uma de João de Barros, do século XVI, e outra de Evanildo Bechara, do século XXI, numa perspectiva da Historiografia da Linguística. Seguindo os princípios de Koerner (2014), deve-se explanar: quais são os autores e as obras apresentadas e qual o clima de opinião a que correspondem (contextualização); de modo analítico, o que esses textos apresentam e quais as suas contribuições (imanência); e de que maneira é possível relacionar essas conclusões com o ensino atual de Língua Portuguesa (adequação). Enfim, este trabalho aponta de que maneira o tempo do pretérito mais-que-perfeito do indicativo foi na primeira gramática da língua portuguesa; quais as possíveis implicações ideológicas das considerações do gramático do século XVI ao tempo verbal; quais as possíveis distinções e semelhanças com a gramática de Evanildo Bechara; e, por fim, quais as reflexões possíveis para o ensino de Língua Portuguesa nas escolas públicas. 


\section{Palavras-chave}

Pretérito mais-que-perfeito. Historiografia Linguística. Ensino Básico.

\section{INTRODUÇÃO}

Para que se faça uso de uma gramática, é importante conhecer suas condições. Neste trabalho, dialogaremos sobre seu aspecto histórico sob a perspectiva da Historiografia Linguística, que contribui para o ensino, por exemplo, o pretérito mais-que-perfeito, tempo verbal escolhido para o estudo deste trabalho, será estudado sob a perspectiva do século XVI de acordo com a historiografia linguística da época.

A Historiografia Linguística, como disciplina inserida nos estudos linguísticos, determina-se a uma investigação metodologicamente informada e à apresentação de acontecimentos passados na evolução da disciplina designada de "linguística" ou "ciências da linguagem" (KOERNER, 2014). Nessa perspectiva, partimos dos princípios de Koerner (2014), propondo um estudo em três partes: quais são os autores e as obras apresentadas e qual o clima de opinião a que correspondem (contextualização); de modo analítico, o que esses textos apresentam e quais as suas contribuições (imanência); e de que maneira é possível relacionar essas conclusões com o ensino atual de língua portuguesa (adequação).

Este trabalho se atém, em um primeiro momento, com os gramáticos João de Barros (1496-1570) e Evanildo Bechara (1928- ). João de Barros, a quem se atribui a autoria da primeira gramática da língua portuguesa (BUESCU, 1978), fez uma breve consideração, em sua obra Grammatica da Lingua Portuguesa (1540), a respeito do tempo verbal escolhido para a análise deste trabalho, tanto quanto à forma simplificada como à sua forma composta. O gramático brasileiro Evanildo Bechara, na Moderna Gramática Portuguesa (2009), também faz algumas considerações com relação ao pretérito mais-que-perfeito e, desta forma, é possível fazer um paralelo com as considerações de João de Barros. Ambos os escritores utilizam-se da vertente do pensamento linguístico a que aderem e do uso da língua na época em que escrevem para compor suas obras e tratar do uso do pretérito mais-que-perfeito.

Entretanto, não nos detivemos em apenas analisar e explanar as contribuições dos autores, mas tentamos adequá-las ao ensino de Língua Portuguesa, 
em que há um conjunto de saberes cuja significação e ressignificação exigem uma criticidade dos alunos diante dos conceitos normativos. As escolas de Educação Básica nas redes públicas de ensino encaram hoje problemas na disciplina de Língua Portuguesa ao abordar o pretérito mais-que-perfeito do modo indicativo por conta do uso cada vez mais escasso da forma simplificada em vista da composta, compreendendo a significação e ressignificação da língua.

Por outro lado, os fundamentos para o ensino de Língua Portuguesa consistem em ampliar o conhecimento linguístico dos educandos permitindo-lhes maior interação social e maior poder de cidadania, conforme dita a Secretaria de Estado da Educação (SEE) de São Paulo (SÃO PAULO, 2012). É esse conhecimento linguístico dos educandos que compreende seu domínio da língua materna, o que nos leva a abordar a gramática normativa, apesar de não se restringir a ela (SÃO PAULO, 2012, p. 32).

Por fim, seguindo o que nos propomos a realizar, devemos tratar dos gramáticos, de suas considerações sobre o período verbal escolhido para estudo e de que maneira podemos utilizar essas contribuições no ensino de língua.

\section{JOÃO DE BARROS}

João de Barros (1496-1570) foi filho ilegítimo do nobre Lopo de Barros e educado no paço real. Autodidata, ampliou sua formação de grande erudição dos clássicos. Humanista e católico, tinha visão crítica capaz de analisar e posicionar-se sobre tudo o que não fosse dogma. Mais tarde, fora Moço de Guarda-Roupa do príncipe Dom João III (1502-1557) e, depois de sua coroação, chegou a exercer diversos cargos públicos, o que lhe permitiu sempre boa influência, acesso aos mais variados documentos e recursos financeiros para suas próprias empresas, até uma malfadada busca de ouro na Capitania do Maranhão no Brasil (BUESCU, 1978, p. 54-59).

O estudioso português tem grande importância pelo seu papel de pioneirismo na formação de uma gramática normativa em língua portuguesa. Sabe-se que, antes dele, Fernão de Oliveira - a quem João de Barros conhecia pessoalmente e a quem chegou a entregar a educação de seus filhos -, em 1536, escrevera a Grammatica da Lingoagem Portuguesa, que, no entanto, não teria a mesma dimensão sistemática, tratando-se de uma "primeira anotação", 
como teria dito o próprio autor (OLIVEIRA, 1536). Por outro lado, a obra de João de Barros é tida como "uma verdadeira gramática, dotada de uma sistematização e dum caráter não só vincadamente pedagógico, mas também normativo" (BUESCU, 1978). João de Barros relata em sua obra sobre a serventia de uma gramática como para "hu modo certo e iusto de falar, \& escreuer" (BARROS, 1540, p. 2). Portanto, a Grammatica da Lingua Portuguesa (1540), de João de Barros, pode ser assumida como a primeira gramática realmente normativa da língua portuguesa.

Durante esse período, as mudanças no cenário ocidental iam desde as descobertas de novas terras às inovações tecnológicas e científicas que moldaram a Europa e a América até o século XVIII. Quanto às descobertas de novas terras, surgiu entre os europeus o "apetite" colonizador e a inevitável necessidade de normatizar a língua portuguesa com o objetivo de impor aos povos conquistados. Fernão de Oliveira menciona em sua obra que "porque milhor he que ensinemos a Guiné cá que sejamos ensinados de Roma" (apud OLIVEIRA, 1536).

Das novidades tecnológicas, destacaremos a criação da imprensa que, conforme Buescu (1978), promoveu e exigiu uma "uniformidade regulamentar da Ortografia, até então anárquica e caprichosa”. De fato, a maior agilidade na publicação de textos permitiria situar as obras em um ambiente autenticamente público, ou seja, em que as questões de estilo ortográfico pessoal estavam submetidas ao entendimento comum e, por isso, exigiria uma ortografia evidentemente comum.

Esteve no auge, então, o que Auroux (1992) chamaria de "segunda revolução técnico-linguística". Tal revolução consiste na gramatização, em que há uma rede homogênea de comunicação centrada, inicialmente, na Europa foi capaz de se espalhar pelo mundo gerando um grande número de publicações de gramáticas, cujas técnicas de descrição e explicação da língua foram compartilhadas entre si. Tais descrições estavam mormente centradas: 1 . na necessidade de se estabelecer um quadro padrão para a língua que assumia caráter administrativo; 2 . no acesso a um corpus de textos sagrados; 3 . no estabelecimento de relações comerciais e políticas internacionais; 4. nas viagens e expedições militares, que visavam o estabelecimento de um domínio extrafronteiro; 5. no proselitismo religioso, especialmente a partir das reformas protestante e tridentina; e 7. no desenvolvimento de uma expansão linguística, interna e externa (cf. AUROUX, 2009, p. 50). 
Essa rede de comunicação permitiu a transferência de um modelo teórico e metodológico, contribuindo para a compreensão da gramática de João de Barros. O português passa a fazer parte de uma célebre lista de gramáticos normativos das línguas vernáculas, que marcaram a história escrevendo obras durante o final do século XV e ao longo do século XVI.

\section{EVANILDO BECHARA}

Evanildo Cavalcante Bechara (1928- ) é um gramático pernambucano da cidade de Recife. Órfão de pai desde os 11 anos, passa a viver no Rio de Janeiro, onde gradua-se em Letras pela então Faculdade do Instituto La-Fayette. Em 1961, publicou como tese de sua livre-docência a "Moderna Gramática da Língua Portuguesa”, cuja principais influências são do filólogo Manuel Said Ali Ida (1861-1953) e do linguista Eugenio Coșeriu (1921-2002).

Bechara inicia sua carreira nas Ciências da Linguagem em um momento em que a Linguística se consolida no cenário internacional e em que as Ciências Sociais ganham mais importância, de forma a determinar os estudos linguísticos para o que mais tarde seria chamado de Pragmática. Dessa maneira, Evanildo Bechara terá sua obra situada em um novo contexto científico em que a Língua e a linguagem serão progressivamente associadas à realidade dos falantes, desde as questões de fundo histórico, sociológico, psicológico até à interatividade do mundo digital e suas novas formas de comunicação e de linguagem. Consideremos, assim, as referências que contribuíram com sua formulação de norma diante desse cenário.

Bechara, quando cursava o ginásio da época, entrou em contato com a obra Lexeologia do portuguez historico (1921), de Said Ali, e notara a presença da referência ao "falante", uma novidade naquele momento (BASTOS et al., 2008). Bechara passa, então, a ler outras obras do filólogo, conheceu-o e frequentou sua casa. Em 1954, em concurso para o Colégio Dom Pedro II, apresentou a tese "Estudos sobre o meio de expressão do pensamento concessivo em português" - a influência do filólogo chegou a ser considerada pelo próprio autor como do "espírito de Said Ali” (BASTOS et al., 2008).

Com relação à influência do teuto-romeno Eugenio Coșeriu, Bechara testemunha como "grande lição" a "preservação dos estudos sobre a linguagem realizados antes da institucionalização da Linguística” (BASTOS et al., 2008). 
Coșeriu foi professor no Uruguai e proferiu três conferências na Biblioteca Nacional do Brasil. Foi nesse período que o gramático brasileiro aprofundou seus conhecimentos sobre o linguista, chegando a trabalhar na tradução de Lições da Linguística Geral (BASTOS et al., 2008). De modo geral, Coșeriu influiu no modo de Bechara pensar língua, concernindo numa visão linguística de universalidade, o que significa que os estudos sobre a linguagem deve considerar, ao invés de hierarquizar, todos os aspectos de seu objeto de estudo: variações linguísticas, fala, texto, discurso, sistema etc.

A partir dessas influências, o gramático apresenta a norma perpassando e respondendo às correntes linguísticas, sem deixar de ser coerente com a tradição normativa brasileira.

\section{GRAMÁTICA DA LÍNGUA PORTUGUESA, 1540}

Como já dissemos, a Gramática da Lingua Portuguesa (1540), de João de Barros (1496-1570), foi escrita num clima intenso de trabalhos na área da gramática, cuja variadas razões incluíam a padronização e o ensino da língua. Isso reflete numa escolha bastante pedagógica de João de Barros: o gramático compara as classes gramaticais às peças de um tabuleiro de xadrez.

A partir dessa analogia com o xadrez, a classe gramatical do verbo, por exemplo, é considerada como o rei (juntamente com o "nome"), ao qual é dado o conceito de "uóz ou palaura que demónstra obrár algua cousa" (BARROS, 1540, p. 18). Vale ressaltar que este rei não é, segundo o gramático, declinado à maneira dos "nomes" e "pronomes", mas "coniugase per módos e tempos" (BARROS, 1540, p. 18).

Observa-se desde o início de sua gramática que o renascentista João de Barros parte sempre dos usos do latim e de terminologias gregas, a última em menor escala. Por isso, a distinção entre declinação e conjugação é importante, uma vez que, a partir dessa distinção, é que se forma uma gramática autenticamente vernácula.

Ao descrever os tempos verbais, antes mesmo dos modos, de modo inverso ao que fez o gramático espanhol António de Nebrija (1441-1522), contemporâneo de Barros, o gramático português comparou-os aos tempos latinos, nomeando-os como "presente, passádo por acabar, passádo acabádo, passádo mais que acabado, uindouro, ou futuro.” (BARROS, 1540, p. 20). Esses tempos 
correspondem ao modo indicativo, embora o autor não tenha assim denominado, pois é o modo que contém todos os tempos verbais. Já indicamos aqui a ausência do nosso futuro do pretérito.

Tendo apresentado os tempos verbais, segue um conjunto de exemplos e seus conceitos para cada tempo verbal, respectivamente - mais uma vez, do modo indicativo. O passado mais que acabado é exemplificado pela sentença "Eu amára", seguido de uma outra exemplificação "Eu tinha amádo" (BARROS, 1540, p. 20). Aqui, vemos dois modos de se usar o mesmo tempo verbal, caso exclusivo do passado mais que acabado.

É importante ressaltar que o autor cita a segunda forma ("Eu tinha amádo") caracterizando-a como "soprindo per rodeo". Em outro momento, Barros (1540, p. 25) deixa claro que essa expressão se refere "pera significár alguus que os Latinos tem, de que nós carecemos”.

Em seguida, temos o conceito que determina o tempo em questão como “per o qual tempo demonstramos ter dádo fim á óbra” (BARROS, 1540, p. 20). A definição, entretanto, não a distingue do passado acabado. O passado acabado é exemplificado antes do passado mais que acabado sem, entretanto, ser definido, o que nos faz supor que a conceituação de uma seja a mesma para a outra.

(...) Passado acabádo: como quando disser. Eu amey. Passado mais que acabado: como, Eu amára, ou soprindo per rodeo: dizendo. Eu tinha amádo, per o qual demonstramos ter dado fim á obra (BARROS, 1540, p. 20).

Assim, temos as contribuições de João de Barros para a conceituação de verbos e dos tempos verbais, assim como suas caracterizações e exemplificações.

\section{MODERNA GRAMÁTICA PORTUGUESA, 2009}

A gramática de Evanildo Bechara (1928- ) teve sua primeira edição em 1961, em momento em que as mudanças no cenário linguístico já estavam em andamento, sobretudo no Brasil. Por isso, desde a primeira edição, há um intuito de pôr o estudo da língua portuguesa a par das pesquisas linguísticas que estavam em pleno vapor nos Estados Unidos e Europa. A $37^{\underline{a}}$ edição (2009) mantém esse paradigma, embora "revista, ampliada e atuali- 
zada", o que significa que considera de maneira mais atual uma "leitura atenta dos teóricos da linguagem" (BECHARA, 2009, p. 19). Em outras palavras, a edição faz importantes considerações sobre o que já se tornou paradigma no pensamento linguístico, sem, no entanto, abrir mão de seu caráter normativo.

A partir dessas características, Bechara inicia a descrição do verbo como uma unidade de "significado categorial que se caracteriza por ser um molde pelo qual organiza o falar seu significado lexical” (BECHARA, 2009, p. 209). Ademais, o autor amplia essa descrição em "Considerações gerais", divididas em: 1. distinção de verbos nocionais e relacionais; 2 . categorias verbais segundo Roman Jakobson; e 3. tempo e aspecto segundo Eugenio Coșeriu (BECHARA, 2009, p. 209-213).

Desta maneira, a primeira seção introduz um questionamento à distinção de verbos nocionais e relacionais, parecendo concluir que em termos sintáticos a distinção não se justifica, embora tenha validade em termos lexicais. Assim, Bechara considera orações formadas a partir de verbos semelhantes ao verbo "ser" como verdadeiramente verbais.

Na segunda seção, as conjugações verbais são consideradas como formas pelas quais os verbos mantêm seu mesmo significado lexical, embora ocorram mudanças de significados categoriais. Entre as categorias existentes, conforme as contribuições de Coșeriu, estariam o modo e o tempo, consideradas como de determinação do discurso, embora a primeira seja entendida como a que afeta participantes e a segunda como a que não afeta, uma vez que são os participantes que constituem o discurso. O tempo é compreendido como a função verbal associada ao acontecimento, quer seja no ato da fala, quer seja em comunicado, apresentando-se como presente, passado e futuro.

$\mathrm{Na}$ terceira seção, Bechara postula que as categorias tempo e aspecto estão ligadas entre si nas línguas românicas, de modo que o tempo determina posições verbais. Os tempos verbais apresentados, portanto, na língua portuguesa, teriam níveis de tempo caracterizados como atual e inatual, distinguindo-se do presente e outros tempos, por subentender o aspecto no tempo verbal. Assim, seria de nível atual o que corresponde ao que está no presente, mesmo que não esteja formulado no tempo verbal do presente, e estaria no nível inatual o que não compreende a mesma atualidade, independente se está ou não formulado em outros tempos verbais. 
Nessa mesma seção, o gramático traz a concepção de perspectiva que corresponde à relação do falante com a ação verbal (BECHARA, 2009, p. 214). Aqui está exposto, pela primeira vez, o pretérito mais-que-perfeito como ação verbal inatual de um passado retrospectivo em relação à perspectiva do falante diante do pretérito imperfeito em um presente paralelo. Em outras palavras, o pretérito mais-que-perfeito é compreendido como uma ação do passado em relação a um outro passado, tido como imperfeito. Só é possível compreender uma ação mais que acabada se há a perspectiva de outra ação já acabada, mesmo que seu fim não esteja exposto ainda.

Na perspectiva secundária (BECHARA, 2009, p. 215), é que se demonstra que, mesmo já havendo um enunciado formulado com perspectiva, é possível, a partir de outra delimitação espaço-temporal, mais uma relação de perspectiva conforme mostram os quadros abaixo:

Quadro 1

\begin{tabular}{|c|c|c|c|}
\hline & Passado Retrospectiva & Presente Paralela & Futuro Prospectiva \\
\hline ATUAL & Fiz & Faço & Farei \\
\hline INATUAL & Fizera & Fazia & Faria \\
\hline
\end{tabular}

Fonte: Elaborado pelo autor.

Quadro 2

\begin{tabular}{|c|c|c|c|}
\hline PRESENTE & $\begin{array}{c}\text { Tenha feito } \\
\text { Tinha feito }\end{array}$ & $\begin{array}{c}\text { FAÇO } \\
\text { FAZIA }\end{array}$ & $\begin{array}{c}\text { Vou fazer } \\
\text { la fazer }\end{array}$ \\
\hline PASSADO & $\begin{array}{c}\text { Tive feito } \\
\text { Tivera feito }\end{array}$ & $\begin{array}{c}\text { FIZ } \\
\text { FIZERA }\end{array}$ & $\begin{array}{c}\text { Fui fazer } \\
\text { Fora fazer }\end{array}$ \\
\hline \multirow{2}{*}{ FUTURO } & $\begin{array}{c}\text { Terei feito } \\
\text { Teria feito }\end{array}$ & FAREI & Irei fazer \\
& FARIA & Iria fazer \\
\hline
\end{tabular}

Fonte: Elaborado pelo autor.

No quadro 1, vemos as perspectivas primárias do falante em relação a tempos verbais secundários em níveis. Assim, quando o presente atual é "faço", sua perspectiva retrospectiva remete ao atual "fiz" e sua perspectiva prospectiva é o atual "farei". Enquanto, se a perspectiva parte do presente inatual "fazia", as perspectivas retrospectiva e prospectiva serão respectivamente "fizera" e "faria". No quadro 2, as seis formas verbais, todas em perspectiva, 
geram outras perspectivas, formuladas em locução, de modo que "tivera feito" corresponde à perspectiva secundária de "fizera".

Somente depois dessas considerações a respeito do verbo e de suas categorias e relações tempo-aspecto, a Moderna Gramática Portuguesa (2009) expressa de maneira mais simples os tempos verbais em três seções: presente, passado e futuro (BECHARA, 2009, p. 221), inserindo o pretérito mais-que-perfeito na seção passado.

Da mesma maneira que a Moderna Gramática Portuguesa (2009) expõe com simplicidade os tempos verbais, apresenta diversos outros tópicos em que faz considerações sobre características dos verbos. A caracterização da locução verbal e dos verbos auxiliares, em que Bechara (2009, p. 230-231) exemplifica o pretérito mais-que-perfeito de forma composta com os auxiliares "ter" e "haver", o último considerado raro, é de suma importância nesse trabalho. Adiante, Bechara menciona, também, o uso do verbo “ser”, ainda que mais raro que o uso do verbo "haver".

$\mathrm{O}$ autor, dando importância aos morfemas na formação das conjugações verbais, descreve os sufixos verbais, entre os quais o (-RA) e o (-RE) átonos caracterizariam o pretérito mais-que-perfeito, sendo sua forma primitiva o tema das conjugações no pretérito perfeito, ambos no indicativo (BECHARA, 2009, p. 234-237).

\section{CONTRIBUIÇÕES DO RENASCIMENTO E DA PÓS-MODERIIDADE PARA OS ESTUDOS DE LÍNGUA}

Percebemos, ao analisar as duas gramáticas, que ambos os autores fazem parte de períodos em que a ruptura dos estudos linguísticos levou-os a certas inovações coerentes com o momento a que correspondem. Essas disposições contribuem para uma melhor compreensão da língua e de sua estrutura, permitindo a qualquer estudante um olhar crítico da normativa da língua portuguesa.

Para Barros (1496-1570), é partir da distinção do verbo como "palavra que demonstra obrar alguma coisa" e da distinção entre declinação e conjugação que encontramos os modos e os tempos verbais. Nesse sentido, Barros conduz a descrição da língua para a organização linguística da classe gramatical em sua natureza, estado e uso - o que é, como é e como se fala. Ainda que um raciocínio lógico vertical, em que a natureza encontra-se em primeira escala, o 
estado (ou caracterização) em segunda escala, e, por último, as formas, tal raciocínio ainda revela o pensamento pós-medieval de caráter aristotélico, tomista, mas é, também, mais experimental, no momento em que se dispõe a descrever uma língua não gramaticalizada. Este aspecto mais experimental revela o pensamento em transição para o movimento científico, caracterizado pelas mudanças de parâmetros provocadas pelas pesquisas de Nicolau Copérnico (1473-1543) e Galileu (1564-1642) dos séculos XV e XVI, que conduziam a investigação científica para a demonstração de teses e consequentes provas.

Para Bechara (2009), a definição da palavra como uma unidade de "significado categorial que se caracteriza por ser um molde pelo qual organiza o falar seu significado lexical” abre um leque de questões linguísticas que só farão sentido se compreendidas corretamente. Desse modo, vemos que a pós-modernidade, mesmo para um autor que procura respeitar a tradição, impera em uma forma analítica de pensamento. O conceito é uma síntese de aspectos a ser parte a parte descrito, formando hiperlinks que se correspondem permitindo, por exemplo, que a leitura aconteça de forma fragmentada. Um leitor da Moderna Gramática Portuguesa (2009) pode pesquisar primeiramente sobre os conceitos verbais de Roman Jakobson (1896-1982) para depois entender o que seriam verbos nocionais e relacionais. Outra característica visível é a quantidade de conceitos e ideias que representam bem a pluralidade de pensamentos e a rapidez de informações tão comuns ao século XXI.

Encontramos, dessa maneira, duas visões que, se por um lado assemelham-se em trilhar um caminho de continuidade, distinguem-se nos objetivos a que se propõe e, por isso, na forma que descrevem o mesmo objeto.

Se por um lado, João de Barros ocupa-se em descrever a língua propondo a atenção com a gramática latina, por outro, propõe uma nova escrita em língua, disposta a se adequar aos vernáculos. Da mesma maneira, Evanildo Bechara preocupa-se em citar a tradição gramatical da língua portuguesa e de fazer referência a alguns estudiosos mais antigos, mas aprofunda-se nas questões linguísticas que emergem a partir da Pragmática.

Divergem, no entanto, Barros e Bechara, na condução de uma escrita que, para o primeiro, é logicamente sequencial, dando conceito por conceito, exemplo por exemplo. Já para o segundo, a escrita é logicamente analítica, propondo a abertura dos conceitos e seus aprofundamentos, o autor ocupa-se muito menos de exemplificações e mais com resultados práticos dentro da lógica linguística a que se atém. 
A mudança nos meios de se investigar o mesmo objeto linguístico, embora não interfira no objeto em si, reflete as transformações do pensamento a que os homens estão condicionados. Em outras palavras, compreender como um mesmo objeto pode ser visto de maneiras distintas oferece não só uma visão mais ampla do objeto, como uma melhor compreensão dos mecanismos humanos de conceituação, de idealização e de proposição.

Em uma sala de aula, por exemplo, permitir aos alunos a leitura, ainda que superficial, de ambos os textos, possibilitaria a eles concluir que, conforme novas descobertas e novas relações se estabelecem, igualmente transforma-se o pensamento científico. No caso da língua, esse fator se relaciona com as variações linguísticas, não somente históricas, mas também geográficas, culturais e sociais. O objetivo, nesse caso, é fazer com que, por meio da metalinguagem possibilitada pelas gramáticas, os educandos passem de uma condição passiva em relação à norma, para uma condição crítica.

Assim, cumprem-se os objetivos esperados pelo ensino de Língua Portuguesa, ampliando a capacidade de leitura, escrita e interpretação dos alunos, proporcionando-lhes uma visão crítica do mundo e das variações linguísticas e posicionando-os de maneira ativa quanto ao uso da língua, seja ela de acordo com a norma-padrão ou em distinção dela. Vale ressaltar que não se espera dos alunos a mesma compreensão de estudantes de língua, mas acreditamos ser possível oferecer esses conhecimentos à Educação Básica com as devidas adequações. Essas adequações para as aulas, obviamente, são de cargo do professor, pois dependem das condições de aprendizagem dos alunos, as quais são por ele conhecidas e devem ser por ele avaliadas.

Concluímos, assim, os objetivos de apresentar esse estudo sobre o pretérito mais-que-perfeito a partir de das gramáticas de João de Barros e de Evanildo Bechara, correspondentes dos séculos XVI e XXI, a fim de contribuir com o ensino de língua portuguesa das escolas de Educação Básica.

\section{João de Barros and Evanildo Bechara, century XVI e XXI grammars: pretérito mais-que-perfeito and the Portuguese language teaching}

\section{Abstract}

This article aims to form a reflection on the teaching of tense-mode pretérito mais-que-perfeito in public schools of Basic Education (High School Level) 
from an analysis of the description of these tenses in two grammars, a grammar from João de Barros (sixteenth century), and another grammar from Evanildo Bechara (twenty-first century), in a perspective of Historiography of Linguistics. Following the principles of Koerner (2014), we explain: who are those authors and their works presented and what the "climate of opinion" that correspond (Context); analytically what these texts present and what their contributions (Immanence); and how it is possible to relate these findings to the current teaching Portuguese (Adequacy). Finally, this paper points out how the pluperfect tense of indicative was described in the first Portuguese Grammar; which were the possible ideological implications of the considerations of such Grammarian of the sixteenth century about that tense; what were the possible distinctions and similarities with the Grammarian Evanildo Bechara; and finally, what are possible reflections for the teaching of Portuguese language in public schools.

\section{Keywords}

Pretérito mais-que-perfeito. Historiography of Linguistics. Brazilian Elementary Education.

\section{REFERÊNCIAS}

ALTMAN, C. História, Estórias e Historiografia da Linguística Brasileira. Todas as Letras, v. 14, n. 1, p. 14-37, 2012.

AUROUX, S. A Revolução Tecnológica da Gramatização. 2. ed. Campinas: Unicamp, 2009.

BARROS, J. de. Grammatica da Lingua Portugesa. Ed. fac-sim. Lisboa [s.n.], 1540.

BASTOS, N. M. B.; PALMA, D. V. (Orgs.). História Entrelaçada: A Construção de Gramáticas e o Ensino de Língua Portuguesa do Século XVI e XIX. Rio de Janeiro: Lucerna, 2004.

BASTOS, N. M. B.; PALMA, D. V. Elos Portugal e Brasil: João de Barros e Anchieta. Revista de Letras, v. 1/2, n. 26, p. 50-57, 2004.

BASTOS, N. M. B.; PALMA, D. V; HACKEROTT, M. M. S.; FACCINA, R. L. S. Homenagem: 80 anos de Evanildo Bechara. Rio de Janeiro: Nova Fronteira, 2008.

BATISTA, R. de O. Introdução à historiografia da linguística. São Paulo: Cortez, 2013. BUESCU, M. L. C. Gramáticos Portugueses do Século XVI. 1. ed. Amadora, Portugal: Bertrand, 1978. 
BECHARA, E. Moderna Gramática Portuguesa. 37. ed. Rio de Janeiro: Nova Fronteira, 2009.

KOERNER, E. F. K. Quatro décadas de historiografia linguística: estudos selecionados. Vila Real, Portugal: Universidade de Trás-os-Montes e Alto Douro (UTAD), 2014.

NEBRIJA, A. Gramática de la Lengua Castellana. Ed. fac-sim. [s.n.], 1492.

OLIVEIRA, F. de. Grammatica da Lingoagem Portuguesa. Ed. fac-sim. Lisboa [s.n.], 1536.

SÃO PAULO (Estado). Secretaria de Estado. Currículo do Estado de São Paulo: Linguagens, códigos e suas tecnologias. 2. ed. São Paulo: SE, 2012.

SWIGGERS, P. História e Historiografia da Linguística: Status, Modelos e Classificações. Revista Eutomia, ano 3, v. 2, 2010.

SWIGGERS, P. Historiografía de la linguística: apuntes y reflexiones. Revista Argentina de Historiografia Linguística, ano 1, v. 1, p. 67-76, 2009.

Recebido em 02-03-2017.

Aprovado em 27-03-2017. 